\title{
Genetic Counseling, Personalized Medicine, and Precision Health
}

\author{
Erica Ramos \\ Director, Clinical and Product Development, Geisinger National Precision Health, Geisinger Health System, \\ North Bethesda, Maryland 20852, USA \\ Correspondence: eramos@geisinger.edu
}

Millions of individuals in the United States will have their exomes and genomes sequenced over the next 5 years as the use of genomic sequencing technologies in clinical care grows and as initiatives in personalized medicine and precision health move forward. As a result, we will see a shift away from the patient population of early adopters who pursued direct-toconsumer (DTC) testing and paid thousands of dollars to get their genomes sequenced and toward a different and more diverse set of test takers. Early data suggest that these individuals will have different motivations for pursuing genomic sequencing and will be less knowledgeable about and less confident of the benefits of genetic testing. To serve this growing population, genetic counselors must understand our future patients as well as the changing landscape of genomic testing, DTC offerings, and population sequencing initiatives.

$\mathrm{T}_{\mathrm{s}}^{\mathrm{h}}$ he practice of genetic counseling is facing several significant changes as the promise of personalized medicine is realized. Anytime the status quo shifts, particularly when changes appear to be rapid and all-encompassing, anxiety, concern, consternation, and a penetrating sense of uncertainty can flood in. However, history shows that in the face of change, the field of genetic counseling will be ready-not only to adapt-but to lead. Genetic counseling has seen multiple shifts in the areas in which we practice, in our employers, in the health-care and political landscapes, and in our patient populations. However, the core components of genetic counseling have remained relatively stable, and this stability has enabled us to move nimbly into these new areas of practice. As the promise of personalized medicine is realized, we will leverage that same core to shift once again as we provide services to the increasingly broader swath of people who require our expertise, guidance, and care.

\section{PERSONALIZED, PRECISION, OR INDIVIDUALIZED MEDICINE?}

Although the term "personalized medicine" has become part of the lexicon, there remains a lack of clarity on what this term means and how it differs from related terms, including "precision medicine," "individualized medicine," and others. One common complaint from physicians about the term "personalized medicine" is that it can be perceived as downplaying the extent to

Editors: Laura Hercher, Barbara Biesecker, and Jehannine C. Austin

Additional Perspectives on Genetic Counseling: Clinical Practice and Ethical Considerations available at

www.perspectivesinmedicine.org

Copyright (C) 2020 Cold Spring Harbor Laboratory Press; all rights reserved; doi: 10.1101/cshperspect.a036699

Cite this article as Cold Spring Harb Perspect Med 2020;10:a036699 


\section{E. Ramos}

which they have always practiced medicine in a way that took the personal characteristics of their patients into consideration. And although this is true, the vision of "personalized medicine" as it is portrayed today implies a deeper level of customization, including diagnostic, screening, treatment, and management approaches based on genomics and other factors, and a systematized integration of this customization into care.

One early proposal for how to describe this realignment of medical care came from Dr. Lee Hood, who coined the term "P4 medicine"predictive, personalized, preventive, and participatory. He felt that a single term could not fully represent the scope of how medicine would evolve given advancements in genomics, monitoring devices, and our ability to assess risk (Hood 2008). Although this approach attempted to capture the complexity of a future state in which these characteristics converged, it was not widely adopted. Another suggestion came from the National Research Council's Committee on a Framework for Developing a New Taxonomy of Disease, in a 2011 report called Toward Precision Medicine: Building a Knowledge Network for Biomedical Research and a New Taxonomy of Disease (www.nap.edu/catalog.php? record_id=13284):

Personalized medicine refers to the tailoring of medical treatment to the individual characteristics of each patient. It does not literally mean the creation of drugs or medical devices that are unique to a patient, but rather the ability to classify individuals into subpopulations that differ in their susceptibility to a particular disease or their response to a specific treatment. Preventive or therapeutic interventions can then be concentrated on those who will benefit, sparing expense and side effects for those who will not (PCAST 2008). This term is now widely used, including in advertisements for commercial products, and it is sometimes misinterpreted as implying that unique treatments can be designed for each individual. For this reason, the Committee thinks that the term "precision medicine" is preferable to "personalized medicine" to convey the meaning intended in this report.

Despite the Committee's advocacy, the use of both terms has persisted. Additionally, with the rapid growth of genomics-guided therapies in oncology, the reverse has happened: "Precision medicine" is often used to suggest cancer treatments that are specific to somatic mutations that drive cancer growth. In a blog post addressing this issue, Dr. Muin Khoury, Director of the Office of Public Health Genomics for the Centers for Disease Control and Prevention (CDC), questions, "Does this change in words represent just semantics or is it an important conceptual shift in the scientific understanding of health and disease and its application to treatment and prevention?" (https://blogs.cdc.gov/genomics/ 2016/04/21/shift/). An important extension to his question is whether this terminology will provide useful distinctions for the general population or mask their true concerns, and if that question should guide how these terms are used with genetic counseling patients in practice.

A more recent addition to the lexicon describing this new initiative in medicine is "precision health," which some suggest is a rebranding of personalized medicine in the face of underwhelming success. Although personalized medicine always included a strong aspect of prevention, precision health is presented as having a specific focus on the identification of high-risk individuals and provision of targeted risk mitigation to prevent disease symptoms (Juengst and McGown 2018). This concept extends to precision public health as well, as "there is an emerging list of genomic applications that merit a targeted public health approach to find people with selected genetic conditions (e.g., hereditary breast/ovarian and colorectal cancers and familial hypercholesterolemia)" (Khoury et al. 2016).

\section{SEQUENCING EVERYONE: POPULATION GENOMIC SEQUENCING INITIATIVES}

Regardless of the terminology, genetics and genomics remains central to most applications of personalized medicine. Around the world, major publicly funded research initiatives are underway to assess potential precision public health and personalized medicine benefits, among other goals, via population-scale genomic sequencing. Australia, France, India, Singapore, South Korea, and the United Kingdom have all an- 
nounced genomics initiatives that will sequence tens of thousands to millions of individuals in their countries (https://www.genomeweb.com/ sequencing/illumina-says-population-sequenc ing-dtc-will-continue-grow-long-term).

The United Kingdom's National Health Service (NHS) has completed a significant pilot program in population genomics and upon its completion, announced that they would soon undertake the largest population-scale genomics screening initiative proposed to date. In 2012, Genomics England, a company funded by the Department of Health \& Social Care, announced that they would sequence 100,000 genomes from NHS patients (https://www.genomicsengland.co .uk/about-genomics-england/the-100000-geno mes-project/). This effort was exclusively focused on individuals who had an undiagnosed rare disease that appeared to be genetic and those with cancer, and the project completed the 100,000 th genome in December 2018. In October 2018, Health and Social Care Secretary Matt Hancock announced the expansion of the 100,000 Genomes Project to one million genomes and the intent to sequence 5 million genomes in 5 years, the most ambitious target thus far. Key to the latter announcement was a controversial "genomic volunteering" proposal that would allow individuals to purchase genome sequencing and receive health-related results even if they did not have any medical concerns, with the data going to support a greater research effort. Critics of this proposal highlighted that there were insufficient data on how to use a genome in a "healthy" person and decried the unrolling of a two-tiered health system (https ://www.theguardian.com/society/2019/jan/26/ nhs-to-sell-dna-tests-to-healthy-people-in-pushto-find-new-treatments). In July 2019, an official government consultation called "Advancing our health: prevention in the 2020 s-consultation document" was published confirming the goal of sequencing 5 million people by 2024, including healthy individuals, but stating that it would be free to all NHS patients (https://www.gov.uk/ government/consultations/advancing-our-healthprevention-in-the-2020s/advancing-our-healthprevention-in-the-2020s-consultation-document \#contents).
In the United States, the Million Veterans Program (MVP) began enrolling participants in 2011. As of July 2019, the MVP boasted 750,000 enrolled veterans, including the largest existing cohort of minority participants in the United States (Rubin 2019). In addition to collecting participant questionnaires and electronic health record data from the Veterans Administration, the MVP has performed a combination of genotyping and exome and genome sequencing on participant samples. Research targets include schizophrenia, bipolar disorder, posttraumatic stress disorder, cardiac disease, metabolic disease, renal disease, and substance abuse (Gaziano et al. 2016).

In 2015, during his State of the Union address, President Barack Obama announced his intention to launch the Precision Medicine Initiative-a population-wide research effort, led by researchers, clinicians and patients, to advance personalized medicine (https://www.whitehouse .gov/the-press-office/2015/01/20/remarks-presi dent-state-union-address-january-20-2015). The National Institutes of Health-funded research initiative, the All of Us Research Program, launched in 2016 with the intent of enrolling a diverse group of participants, with an emphasis on including individuals from groups who have been underrepresented to date in biomedical research. As of May 2019, 143,000 participants were enrolled as direct volunteers or through health-care partner organizations. Of all participants, $53 \%$ are ethnic or racial minorities, which if maintained through the proposed enrollment goal of one million individuals, would surpass the minority cohort size of the MVP (https://www .joinallofus.org/en/in-the-news/nih-says-its-1million-person-health-study-good-start).

In addition to these government-funded research efforts, several health systems have launched population genomic screening efforts focused on their patient populations. These programs each target up to 500,000 participants, use a variety of genetic testing methodologies, and have been enabled to a significant degree by public-private partnerships (Table 1).

The Geisinger Health System MyCode Community Health Initiative (MyCode) was the first study to start sequencing patients in 
E. Ramos

Table 1. Selected public-private population genomic screening initiatives

\begin{tabular}{|c|c|c|c|c|c|}
\hline Project & Collaborators & $\begin{array}{c}\text { Target } \\
\text { population }\end{array}$ & $\begin{array}{c}\text { Year } \\
\text { initiated }\end{array}$ & Assay & Results returned \\
\hline Geisinger MyCode ${ }^{\mathrm{a}}$ & $\begin{array}{l}\text { Regeneron } \\
\text { Pharmaceuticals }\end{array}$ & $\begin{array}{l}\text { Geisinger } \\
\text { patients }\end{array}$ & 2014 & Exome & $\begin{array}{l}60+\text { genes for actionable } \\
\text { disorders }\end{array}$ \\
\hline Renown Healthy & 23andMe & Nevada & 2016 & Array & Ancestry + health \\
\hline Nevada $^{b}$ & Helix & residents & 2018 & Exome & Ancestry + traits \\
\hline Sanford Imagenetics ${ }^{c}$ & Illumina & $\begin{array}{l}\text { Sanford } \\
\text { patients }\end{array}$ & 2018 & Array & $\begin{array}{l}59 \text { genes for actionable } \\
\text { disorders, } \\
\text { pharmacogenomics }\end{array}$ \\
\hline $\begin{array}{l}\text { NorthShore DNA- } \\
10 \mathrm{~K}^{\mathrm{d}}\end{array}$ & Color & $\begin{array}{l}\text { NorthShore } \\
\text { patients }\end{array}$ & 2019 & Genome & $\begin{array}{l}\text { Cancer, cardiac, } \\
\text { pharmacogenomics }\end{array}$ \\
\hline Mayo Clinic ${ }^{e}$ & $\begin{array}{l}\text { Regeneron } \\
\text { Pharmaceuticals }\end{array}$ & $\begin{array}{l}\text { Mayo Clinic } \\
\text { patients }\end{array}$ & $2019^{g}$ & Exome & Planning to research \\
\hline $\begin{array}{l}\text { Intermountain } \\
\text { HerediGene: } \\
\text { Population Study }{ }^{\mathrm{f}}\end{array}$ & $\begin{array}{l}\text { deCODE Genetics/ } \\
\text { Amgen }\end{array}$ & $\begin{array}{l}\text { Utah and } \\
\text { Idaho } \\
\text { residents }\end{array}$ & $2019^{g}$ & Genome & Planned \\
\hline \multicolumn{6}{|c|}{$\begin{array}{l}\text { awww.geisinger.org/precision-health/mycode } \\
\text { bhealthynv.org/ } \\
\text { cimagenetics.sanfordhealth.org/sanford-chip/ } \\
\text { dnorthshore.org/personalized-medicine/our-services/color-genetics-test/ } \\
\text { egenomeweb.com/genetic-research/regeneron-mayo-ink-pact-sequence-genotype-100k-patient-samples } \\
\text { fintermountainhealthcare.org/heredigene }\end{array}$} \\
\hline
\end{tabular}

2014 and remains the largest private cohort to date with almost 250,000 consented participants and 145,000 individuals from whom they have obtained exome sequencing data (D Ledbetter pers. comm.). In 2015, MyCode began to consent patients for return of results for clinically actionable findings following extensive discussions and assessments by the clinical and bioethics teams, community advisory groups, and scientific leaders, as well as patient-participant focus groups (Faucett and Davis 2016). The MyCode Initiative has enabled the study of the return of results protocols and processes in the context of population screening (Schwartz et al. 2018), as well as patient-centric initiatives such as patient-facing genomic (Goehringer et al. 2018) and pharmacogenomic (Jones et al. 2018) laboratory reports. MyCode has also generated data on the prevalence of familial hypercholesterolemia (Abul-Husn et al. 2016), hereditary breast and ovarian cancer (Manickam et al. 2018), and arrhythmogenic right ventricular cardiomyopathy (Haggerty et al. 2017) in an unselected health system research population. Genetic counseling is fundamental to the MyCode Initiative with genetic counselors leading many of these research efforts, and is inclusive of the primary care physicians and specialists who will follow these patients over time.

Although the other studies cited in Table 1 launched more recently and are just starting to generate data, Renown Health has also published findings regarding the frequencies of rare variants across the exome (Cirulli et al. 2019) and the detection of individuals at risk for hereditary cancers and familial hypercholesterolemia (Grzymski et al. 2019), demonstrating the potential for the rapid generation of insights in very large cohorts.

The expanding scope of population screening is not new. One specific example is cystic fibrosis (CF) carrier screening, although the progression has been similar for many other genes and conditions (Fig. 1). Over the years, practice progressed from testing affected individuals only, to familial variant testing, to populationspecific testing, to broad-based testing. As the tested population expands, new insights into the molecular underpinnings of the disease are elucidated. 


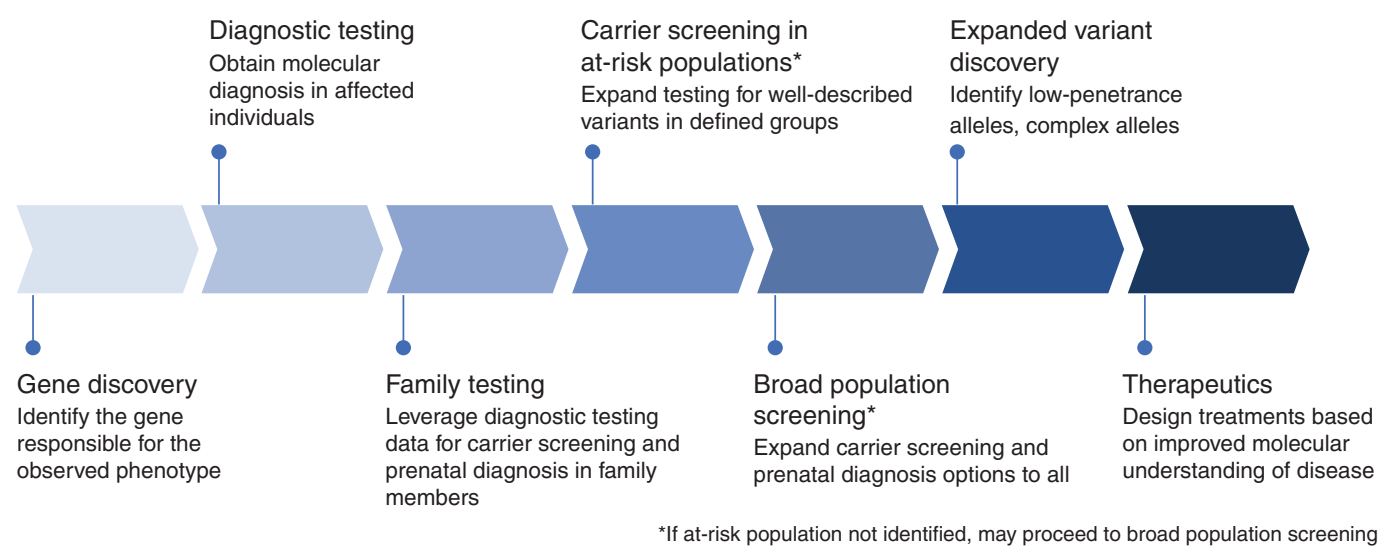

Figure 1. Example of genetic testing trajectory.

For example, in 2004, the American College of Medical Genetics (ACMG) CF Carrier Screening Working Group issued an update to their 2001 CF carrier screening guidelines based on the evidence that had been gathered by screening more than 400,000 individuals. The Working Group recommended changes to testing with regards to two of the original 25 variants. First, it was determined that individuals with CF who carried the I148T mutation had the same second mutation (3199del6), which was subsequently determined to cause the disease. The Working Group recommended that the I148T mutation be removed from the panel. Second, testing for the R117H variant was found to be more complicated than originally understood, as it had to be found in combination with the 5T variant. Although the Working Group recommended keeping $\mathrm{R} 117 \mathrm{H}$ on the panel, they recommended screening for the $5 \mathrm{~T}$ variant as a reflex only when $\mathrm{R} 117 \mathrm{H}$ was identified (Watson et al. 2004).

As next-generation sequencing technologies evolved, pan-ethnic expanded carrier screening (ECS) was introduced. In contrast to historical carrier screening efforts which typically limited testing to specific, predefined variants, ECS sequenced all exons of the gene. Continuing the example of CF, Beauchamp et al. (2018) compared the diagnostic yield of ECS with three ACMG CF screening panels across multiple ethnic backgrounds. The addition of ECS increased disease risk detection by $>80 \%$ in individuals of East, South, and Southeast Asian descent and by $>40 \%$ in individuals of Hispanic and African or African-American descent. Although the performance of the ACMG panels was already high in individuals of European descent, ECS increased disease risk detection by $\sim 20 \%$ in individuals of Northern European and Mixed/ Other Caucasian descent.

When considering an international patient population, these findings suggest that ECS would improve detection rates for most, as individuals from European background are in the minority worldwide. The American College of Obstetricians and Gynecologists and the European Society of Human Genetics have both stated that ECS or ethnic-specific or pan-ethnic carrier screening are acceptable offerings for individuals of reproductive age, assuming the tests are performed with high standards of clinical validity and the content demonstrates clinical utility and severity. However, these organizations have done so while advocating for ECS to be offered in the context of engagement with clinicians, patients, and communities; access to quality genetic counseling services and support; and ongoing outcomes assessments and informed consent (Henneman et al. 2016; American College of Obstetricians and Gynecologists. 2017). Concerns have also been raised about the psychological well-being of patients, including emotional impact, psychological harm, and mis- 


\section{E. Ramos}

understanding of a negative result. Limited data from couples undergoing ECS does not suggest harm in individuals with negative results (Matar et al. 2019) and demonstrates utility in changes to reproductive decision-making (Ghiossi et al. 2018). Further, ethical issues have been raised about the elimination of individuals with certain genetic disorders and equitable access because of ability/willingness to pay (Clarke et al. 2018).

Similar concerns have been put forward about population genomic screening. Yet, multiple cohort studies spanning a range of other testing scenarios and indications including ostensibly healthy individuals who underwent direct-to-consumer (DTC) testing (Bloss et al. 2013; Francke et al. 2013), ApoE testing in individuals at-risk for Alzheimer's disease (Green et al. 2009), clinical exome/genome sequencing (Robinson et al. 2019), and molecular screening in patients with cancer (Best et al. 2019). Although these findings may not hold in all groups who undergo population genomic screening, these studies suggest that people do not widely experience long-lasting harm as a result of genetic testing. Rather, motivations for testing and behaviors when receiving test results, such as limited sharing of results with family members, may be more impactful to assess as population genomic screening grows.

\section{AN EXPANDING AND EVOLVING GENETIC TESTING LANDSCAPE}

In addition to the data being generated by various population-level genomic sequencing initiatives, a substantial wave of increased genetic testing showing sustained growth is that of athome genetic testing, also commonly referred to as DTC genetic testing, direct access testing, or consumer-directed/consumer-initiated testing (Ramos and Weissman 2018). The first significant versions of at-home testing for genetics, as we know it today, came in 2008 with the broad launch of 23andMe's \$399 genetic test (Hamilton 2008; http://ti.me/1fhRH7z). Tests from several other companies entered the market, provoking immediate concern from regulatory authorities. In 2010, the U.S. Government Accountability Office (GAO) commissioned an in- vestigation into several DTC companies and found multiple instances of conflicting results between the companies and other discrepancies (Kutz 2010). Following the Kutz report, the Food and Drug Administration (FDA) sent warning letters to several DTC companies instructing them to stop marketing their tests for health and medical indications. In 2013, following several years of intermittent communication and discussion of regulatory scrutiny, 23andMe was forced to stop providing health information until they developed an FDA-authorized assay and reports. They are currently the only DTC company that can offer FDA-authorized genetic testing for health indications without a physician order. However, although consumers can access these 23andMe genetic tests for healthrelated conditions directly, the FDA specifically states that "results obtained from the tests should not be used for diagnosis or to inform treatment decisions" (FDA News Release 2017). As a result, consumers who receive a positive result and wish to integrate the result into their medical care must confirm the presence of the variant through a clinical laboratory.

Several other laboratories have taken a path that facilitates consumer-directed testing by using third-party physicians to order the test. These labs are offering a variety of tests for adult and pediatric patients (Ramos and Weissman 2018; Weissman et al. 2019). In many of these cases, posttest genetic counseling is provided for individuals with positive results by genetic counselors used by the labs themselves or third-party groups. However, they are rarely fully connected back to the health-care system and the patient is often made to serve as the expert while communicating results back to their treating clinicians.

\section{PUBLIC AWARENESS, PERCEPTIONS, AND PRIORITIES}

Despite excitement in the research, medical, and technology communities, we have yet to see if personalized medicine and genomics will bridge the adoption gap to become routine clinical care. Public Perspectives on Personalized Medicine: A Survey of U.S. Public Opinion, a 2018 
poll conducted for the Personalized Medicine Coalition and GenomeWeb (http://www.per sonalizedmedicinecoalition.org/Userfiles/PMCCorporate/file/Public_Perspectives_on_PM1.pdf), found that $66 \%$ of respondents had not heard of either "personalized medicine" or "precision medicine." Although almost all were positive or neutral to the concept of personalized medicine when it was presented, many respondents immediately jumped to practical concerns:

\begin{abstract}
When shown a list of known concerns, most said they have major concerns that a test might not be covered by their insurer (62\%), they might not be able to afford personalized medicine (59\%), or that test results could be used to deny coverage for a treatment (52\%) or affect long-term care or life insurance policies (51\%). Only 10\% of Americans indicated that they are aware of the Genetic Information Nondiscrimination Act, which prohibits employers or health insurers from asking for genetic test results when making employment or coverage decisions.
\end{abstract}

This study indicates that the intricacies of the terminology are not important to our patients and, more importantly, suggests that they may attribute certain characteristics to any incarnation of "personalized medicine," including that it is risky and expensive. If these perceptions remain unaddressed, fewer people may benefit from these medical advances.

A second 2018 poll, conducted by The Associated Press-NORC Center for Public Affairs Research, focused more on genetic testing specifically. They found that only $17 \%$ of respondents had taken a genetic test themselves and the vast majority of those $(65 \%)$ reported that they had undergone testing to learn more about their heritage or family history, which suggests that many of these individuals may have pursued DTC ancestry testing rather than a clinical genetic test. Only $14 \%$ of those who had taken a genetic test reported having amniocentesis or genetic counseling during pregnancy, which may be more indicative of clinical testing. This represents just 27 out of the 1109 respondents, or $2.4 \%$, of all those who were polled. Historically, patients primarily learned of genetic testing by experts such as genetic counselors, and clinical genetic testing was predominantly of- fered for diagnostic purposes and within the health-care system. Although most individuals who present for genetic counseling will not have had any genetic testing, a larger swath will have had some experience with genetics-good or bad-without any expert interpretation, guidance, or support. Additionally, they are more likely to have had tests that may contain information about health-related conditions but are not of the clinical quality needed to guide medical care.

As one of the key proposed advantages of personalized medicine is disease prevention, the willingness to learn about risk is critical. Seventy-one percent of individuals under age 40 reported that they would want to know if they "carried the gene" for an incurable disease. This dropped to $53 \%$ for individuals age 40 and up.

Finally, this poll suggests that there is a need for initiatives to convey accurate information about the utility and accuracy of genetic testing. When asked how reliable genetic tests were at diagnosing certain conditions, 7\% said not very or not at all reliable. Confidence was lower when asked how reliable genetic testing was at predicting whether a person might develop certain diseases or conditions (11\% said not very or not at all reliable) (Genetic Testing: Ancestry Interest, But Privacy Concerns. Chicago: APNORC. https://reports.norc.org/issue_brief/gen etic-testing-ancestry-interest-but-privacy-con cerns/). As those who are unaffected but concerned about disease risk and prevention or who learn about their risk via consumer-directed tests or research efforts begin to present for genetic counseling services, these preconceptions will need to be addressed.

A key takeaway from these two studies, as well as the population genomic screening studies conducted to date, is that genomic testing is not commonplace nor has it penetrated into the zeitgeist of most communities. This is particularly true in underrepresented communities as, with the exception of the MVP, most testing has been performed in individuals of European descent. For instance, despite the rapid growth in the at-home genetic testing market, 23andMe's research database of more than five million people has about 845,000 who were identified as 


\section{E. Ramos}

African-American, East Asian, Middle Eastern, South Asian, or "other" and 820,000 who were identified as Latino (https://research.23andme .com/research-innovation-collaborations/). However, with the announcements of international screening programs in non-European countries and the efforts of the All of Us Research Program to focus on underrepresented minorities, that is starting to shift.

This limitation is mirrored in the demographics of the field of genetic counseling and other professions. In the 2019 Professional Status Survey from the National Society of Genetic Counselors, $90 \%$ of respondents identified as White (https://www.nsgc.org/page/whoaregene ticcounselors). This lack of diversity plagues most health-care specialties, and the genetic counseling profession will need to identify and address the barriers to entry for individuals from ethnic minority and other excluded backgrounds. In addition to training more professionals to provide genetic counseling who represent the patient populations, we must also ensure that the entire workforce is provided the tools for cultural competence. As Dr. Rhea W. Boyd stated in The Lancet, "To be clear, nonwhite patients should not require a racematched provider to receive a standard of care that is equitable and dignified" (Boyd 2019). Although cultural competence is core to the training and continuing education of genetic counselors, to optimally serve a more diverse population and ensure that all people have the opportunity to benefit from advances in personalized medicine and precision health, our cultural competence must continue to grow (McGinniss et al. 2018).

\section{GENETIC COUNSELING: THE KEYSTONE}

Millions of individuals worldwide will be sequenced in the next few years, and it is clear that genetic counselors will need to play a significant role in shepherding these personalized medicine and precision health efforts forward, from research and health system initiatives to population sequencing initiatives to DTC genetic testing. There are limited studies looking at the impact of genetic counseling in efforts of this scale, both in terms of the cohort size and the quantity of genomic information. Those available paint a positive picture about the importance of genetic counseling, but also highlight the need to adapt counseling models and service delivery to fit the needs of different patient populations. Additionally, and not surprisingly, the motivations of these patients can differ from those seen for diagnostic testing.

Sweet et al. (2017) report on individuals who were part of a Coriell Personalized Medicine Collaborative study. Each participant received a report assessing their risks for 19 potentially actionable complex diseases and seven pharmacogenomic drug reports. Participants could request genetic counseling appointments at any time and the content of the counseling appointment was driven by patient questions and concerns. Of the 51 individuals who were interviewed about their experience, the majority reported a positive impression of genetic counseling and a desire to access genetic counseling in the future if additional results were returned. Key comments reflected the ability of the counselor to synthesize information for them: One participant said she joined the study because of the option to see a genetic counselor and noted it was important to "have somebody with expertise to really give me the insight on what it all means and how it all fits together was what I was looking for" (female, age 54). Another said that her counselor "gave me a tremendous amount of interpretation. It was just very helpful to me. He was able to say well look, this is what this means" (female, age 68).

However, the participant feedback also suggests a need to consider alternatives to traditional service delivery models and flexibility in the content and length of genetic counseling services, which should be considered strongly by counselors providing services for personalized medicine patients.

Schmidt et al. (2019) present data from 70 patients seen over the course of 2 years for genetic counseling following exome or genome sequencing. Similar to Sweet et al. the counselors followed a Reciprocal Engagement Model for their counseling, allowing the client to set the priorities of the session throughout. During the sessions, patients were determined to be 
one of three patient types based on their motivations for testing: (1) the "healthy and curious" who were not expecting any findings based on their histories but interested in any potential "red flags"; (2) those who were interested in a specific finding or risk, either because of family history or a pathogenic variant; and (3) the "undiagnosed and searching" who were suffering from unexplained symptoms and seeking validation and "proof" that they were ill. Interestingly, the motivations expressed by the first two patient types were also reflected in another study of 543 early adopters pursuing elective genome sequencing, but the "undiagnosed and searching” type was not (Zoltick et al. 2019). This third group may represent a shift from the very early adopter population, and one that may especially benefit from genetic counseling, as the authors note that these patients expressed frustration, despair, defeat, desperation, and hopelessness with their physicians and the health-care system.

\section{CONCLUSION}

As the genetic counselor workforce grows and our roles expand, there are professional skills and areas of focus that will become increasingly important. Training programs are evolving to incorporate bioinformatics and variant interpretation and to view long-standing hallmarks of genetic counseling such as ethics, education, counseling, and cultural competence through a genomic lens (Hooker et al. 2014). Although the scope of the changes in the genomics landscape appear vast, genetic counselors have the training, professional resources, and continuing education to adapt and thrive in this evolving environment.

\section{REFERENCES}

Abul-Husn NS, Manickam K, Jones LK, Wright EA, Hartzel DN, Gonzaga-Jauregui C, O'Dushlaine C, Leader JB, Lester Kirchner H, Lindbuchler DM, et al. 2016. Genetic identification of familial hypercholesterolemia within a single U.S. health care system. Science 354: pii:aaf7000.

American College of Obstetricians and Gynecologists. 2017. Carrier screening in the age of genomic medicine. Committee Opinion No. 690. Obstet Gynecol 129: e35-e40.
Beauchamp KA, Muzzey D, Wong KK, Hogan GJ, Karimi K, Candille SI, Mehta N, Mar-Heyming R, Kaseniit KE, Kang HP, et al. 2018. Systematic design and comparison of expanded carrier screening panels. Genet Med 20: 5563. doi:10.1038/gim.2017.69

Best MC, Bartley N, Jacobs C, Juraskova I, Goldstein D, Newson AJ, Savard J, Meiser B, Ballinger M, Napier C, et al. 2019. Patient perspectives on molecular tumor profiling: "why wouldn't you?". BMC Cancer 19: 753. doi:10 $.1186 / \mathrm{s} 12885-019-5920-\mathrm{x}$

Bloss CS, Wineinger NE, Darst BF, Schork NJ, Topol EJ. 2013. Impact of direct-to-consumer genomic testing at long term follow-up. J Med Genet 50: 393-400. doi:10 .1136/jmedgenet-2012-101207

Boyd RW. 2019. The case for desegregation. Lancet 393: 2484-2485. doi:10.1016/S0140-6736(19)31353-4

Cirulli ET, White S, Read RW, Elhanan G, Metcalf WJ, Schlauch KA, Grzymski JJ, Lu J, Washington NL. 2019. Genome-wide rare variant analysis for thousands of phenotypes in 54,000 exomes. bioRxiv doi:10.1101/692368

Clarke EV, Schneider JL, Lynch F, Kauffman TL, Leo MC Rosales AG, Dickerson JF, Shuster E, Wilfond BS, Goddard KAB. 2018. Assessment of willingness to pay for expanded carrier screening among women and couples undergoing preconception carrier screening. PLoS One 13: e0200139. doi:10.1371/journal.pone.0200139

Faucett WA, Davis FD. 2016. How Geisinger made the case for an institutional duty to return genomic results to biobank participants. Appl Transl Genom 8: 33-35. doi:10 $.1016 /$ j.atg.2016.01.003

FDA News Release. 2017. Press Announcements-FDA allows marketing of first direct-to-consumer tests that provide genetic risk information for certain conditions. Retrieved from https://www.fda.gov/NewsEvents/ Newsroom/PressAnnouncements/ucm551185.htm

Francke U, Dijamco C, Kiefer AK, Eriksson N, Moiseff B, Tung JY, Mountain JL. 2013. Dealing with the unexpected: consumer responses to direct-access $B R C A$ mutation testing. Peer J 1: e8. doi:10.7717/peerj.8

Gaziano JM, Concato J, Brophy M, Fiore L, Pyarajan S, Breeling J, Whitbourne S, Deen J, Shannon C, Humphries D, et al. 2016. Million veteran program: a mega-biobank to study genetic influences on health and disease. $J$ Clin Epidemiol 70: 214-223. doi:10.1016/j.jclinepi.2015 .09 .016

Ghiossi CE, Goldberg JD, Haque IS, Lazarin GA, Wong KK. 2018. Clinical utility of expanded carrier screening: reproductive behaviors of at-risk couples. J Genet Couns 27: 616-625. doi:10.1007/s10897-017-0160-1

Goehringer JM, Bonhag MA, Jones LK, Schmidlen T, Schwartz M, Rahm AK, Williams JL, Williams MS 2018. Generation and implementation of a patient-centered and patient-facing genomic test report in the EHR. EGEMs (Wash DC) 6: 14. doi:10.5334/egems.256.

Green RC, Roberts JS, Cupples LA, Relkin NR, Whitehouse PJ, Brown T, Eckert SL, Butson M, Sadovnick AD, Quaid KA, et al. 2009. Disclosure of APOE genotype for risk of Alzheimer's disease. N Engl J Med 361: 245-254. doi:10 .1056/NEJMoa0809578

Grzymski JJ, Elhanan G, Smith E, Rowan C, Slotnick N, Dabe S, Schlauch K, Read R, Metcalf WJ, Lipp B et al. 2019. Population health genetic screening for tier 1 inher- 
E. Ramos

ited diseases in Northern Nevada: $90 \%$ of at-risk carriers are missed. bioRxiv doi:10.1101/650549.

Haggerty CM, James CA, Calkins H, Tichnell C, Leader JB, Hartzel DN, Nevius CD, Pendergrass SA, Person TN, Schwartz M, et al. 2017. Electronic health record phenotype in subjects with genetic variants associated with arrhythmogenic right ventricular cardiomyopathy: a study of 30,716 subjects with exome sequencing. Genet Med 19: 1245-1252. doi:10.1038/gim.2017.40

Hamilton A. 2008. INVENTION OF THE YEAR 1. The retail DNA test. Time Magazine. Retrieved from http ://content.time.com/time/specials/packages/article/0,28804 ,1852747_1854493,00.html

Henneman L, Borry P, Chokoshvili D, Cornel MC, van E CG, Forzano F, Hall A, Howard HC, Janssens S, Kayserili $\mathrm{H}$, et al. 2016. Responsible implementation of expanded carrier screening. Eur J Hum Genet 24: e1-e12. doi:10 .1038/ejhg.2015.271

Hood L. 2008. A personal journey of discovery: developing technology and changing biology. Annu Rev Anal Chem (Palo Alto Calif) 1: 1-43. doi:10.1146/annurev.anchem.1 031207.113113

Hooker GW, Ormond KE, Sweet K, Biesecker BB. 2014 Teaching genomic counseling: preparing the genetic counseling workforce for the genomic era. J Genet Counsel 23: 445-451. doi:10.1007/s10897-014-9689-4

Jones LK, Rahm AK, Gionfriddo MR, Williams JL, Fan AL, Pulk RA, Wright EA, Williams MS. 2018. Developing pharmacogenomic reports: insights from patients and clinicians. Clin Transl Sci 11: 289-295. doi:10.1111/cts .12534

Juengst ET, McGown ML. 2018. Why does the shift from "personalized medicine" to "precision health" and "wellness genomics" matter? AMA J Ethics 20: E881-E890. doi:10.1001/amajethics.2018.881

Khoury ML, Iademarco MF, Riley WT. 2016. Precision public health for the era of precision medicine. Am J Prev Med 50: 398-401. doi:10.1016/j.amepre.2015.08.031

Kraft SA, Schneider JL, Leo MC, Kauffman TL, Davis JV, Porter KM, McMullen CK, Wilfond BS, Goddard KAB. 2018. Patient actions and reactions after receiving negative results from expanded carrier screening. Clin Genet 93: 962-971. doi:10.1111/cge.13206

Kutz G. 2010. Direct-to-consumer genetic tests misleading test results are further complicated by deceptive marketing and other questionable practices. United States Government Accountability Office. Retrieved from https://doi.org/Se rial No. 111-138

Manickam K, Buchanan AH, Schwartz MLB, Hallquist MLG, Williams JL, Rahm AK, Rocha H, Savatt JM, Evans AE, Butry LM, et al. 2018. Exome sequencing-based screening for $B R C A 1 / 2$ expected pathogenic variants among adult biobank participants. JAMA Netw Open 1: e182140. doi:10.1001/jamanetworkopen.2018.2140

Matar A, Hansson MG, Höglund AT. 2019. "A perfect society"-Swedish policymakers' ethical and social views on preconception expanded carrier screening. J Community Genet 10: 267-280. doi:10.1007/s12687-018-0389-x

McGinniss MA, Tahmassi AG, Ramos E. 2018. Towards cultural competence in the genomic age: a review of current health care provider educational trainings and interventions. Curr Genet Med Rep 6: 187-198. doi:10.1007/ s40142-018-0150-0

PCAST (President's Council of Advisors on Science and Technology). 2008. Priorities for personalized medicine. President's Council of Advisors on Science and Technology, September 2008. Available at http://www.whitehouse .gov/files/documents/ostp/PCAST/pcast_report

Ramos E, Weissman SM. 2018. The dawn of consumer-directed testing. Am J Med Genet C Semin Med Genet 178: 89-97.

Robinson JO, Wynn J, Biesecker B, Biesecker LG, Berhardt B, Brothers KB, Chung WK, Christensen KD, Green RC McGuire AL, et al. 2019. Psychological outcomes related to exome and genome sequencing result disclosure: a meta-analysis of seven Clinical Sequencing Exploratory Research (CSER) Consortium studies. Genet Med. doi:10 .1038/s41436-019-0565-3

Rubin R. 2019. Veterans genomic cohort nearing 1 million. J Am Med Assoc 321: 2395.

Schmidt JL, Maas R, Altmeyer SR. 2019. Genetic counseling for consumer-driven whole exome and whole genome sequencing: a commentary on early experiences. J Genet Couns 28: 449-455.

Schwartz MLB, McCormick CZ, Lazzeri AL, Lindbuchler DM, Hallquist MLG, Manickam K, Buchanan AH, Rahm AK, Giovanni MA, Frisbie L, et al. 2018. A model for genome-first care: returning secondary genomic findings to participants and their healthcare providers in a large research cohort. Am J Hum Genet 103: 328-337. doi:10.1016/j.ajhg.2018.07.009

Sweet K, Hovick S, Sturm AC, Schmidlen T, Gordon E, Bernhardt B, Wawak L, Wernke K, McElroy J, Scheinfeldt $\mathrm{L}$, et al. 2017. Counselees' Perspectives of Genomic Counseling Following Online Receipt of Multiple Actionable Complex Disease and Pharmacogenomic Results: a qualitative research study. J Genet Couns 26: 738-751. doi:10 .1007/s10897-016-0044-9

Watson MS, Cutting GR, Desnick RJ, Driscoll DA, Klinger K, Mennuti M, Palomaki GE, Popovich BW, Pratt VM, Rohlfs EM, et al. 2004. Cystic fibrosis population carrier screening: 2004 revision of American College of Medical Genetics mutation panel. Genet Med 6: 387-391. doi:10 .1097/01.GIM.0000139506.11694.7C

Weissman SM, Kirkpatrick B, Ramos E. 2019. At-home genetic testing in pediatrics. Curr Opin Pediatr doi:10 .1097/MOP.0000000000000824

Zoltick ES, Linderman MD, McGinniss MA, Ramos E, Ball MP, Church GM, Leonard DGB, Pereira S, McGuire AL Caskey CT, et al. 2019. Predispositional genome sequencing in healthy adults: design, participant characteristics, and early outcomes of the PeopleSeq Consortium. Genome Med 11: 10. doi:10.1186/s13073-019-0619-9 


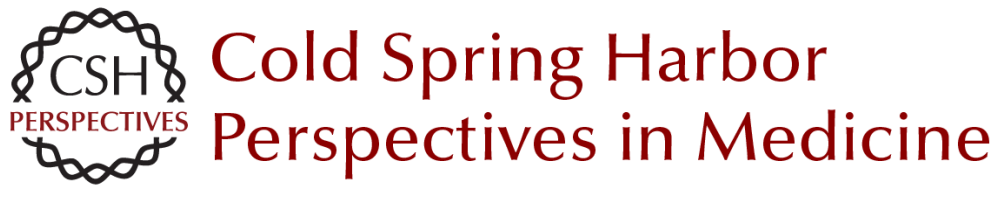

\title{
Genetic Counseling, Personalized Medicine, and Precision Health
}

\author{
Erica Ramos
}

Cold Spring Harb Perspect Med 2020; doi: 10.1101/cshperspect.a036699 originally published online September 30, 2019

\section{Subject Collection Genetic Counseling: Clinical Practice and Ethical Considerations}

Genetic Risk Assessment in Psychiatry Holly Landrum Peay

Birds of a Feather? Genetic Counseling, Genetic Testing, and Humanism Robert Resta

Bridging the Gap between Scientific Advancement and Real-World Application: Pediatric Genetic Counseling for Common Syndromes and Single-Gene Disorders Julie A. McGlynn and Elinor Langfelder-Schwind

Genetic Counseling, Personalized Medicine, and Precision Health Erica Ramos

Tumor-Based Genetic Testing and Familial Cancer Risk Andrea Forman and Jilliane Sotelo

A Person-Centered Approach to Cardiovascular Genetic Testing Julia Platt

Evidence-Based Genetic Counseling for Psychiatric Disorders: A Road Map Jehannine C. Austin

Supporting Patient Autonomy and Informed Decision-Making in Prenatal Genetic Testing Katie Stoll and Judith Jackson
Impact of Emerging Technologies in Prenatal

Genetic Counseling

Blair Stevens

Genetic Counseling and Assisted Reproductive

Technologies Debra Lilienthal and Michelle Cahr

Evolving Roles of Genetic Counselors in the Clinical Laboratory Megan T. Cho and Carrie Guy

Psychological Issues in Managing Families with Inherited Cardiovascular Diseases Jodie Ingles

Informed Consent in the Genomics Era Shannon Rego, Megan E. Grove, Mildred K. Cho, et al.

Predictive Genetic Counseling for

Neurodegenerative Diseases: Past, Present, and Future Jill S. Goldman

Cancer Genetic Counseling--Current Practice and Future Challenges Jaclyn Schienda and Jill Stopfer

Regulating Preimplantation Genetic Testing across the World: A Comparison of International Policy and Ethical Perspectives Margaret E.C. Ginoza and Rosario Isasi

For additional articles in this collection, see http://perspectivesinmedicine.cshlp.org/cgi/collection/ 